\title{
Facile Synthesis of Graphene/ZnO Composite as an Anode with Enhanced Performance for Lithium Ion Batteries
}

\author{
Yanhong Zhao, ${ }^{1,2}$ Gang Chen, ${ }^{1}$ and Yu Wang ${ }^{1}$ \\ ${ }^{1}$ Department of Chemistry, Harbin Institute of Technology, Harbin 150001, China \\ ${ }^{2}$ College of Enviromental and Chemical Engineering, Heilongiiang University of Science and Technology, Harbin 150022, China
}

Correspondence should be addressed to Gang Chen; gchen@hit.edu.cn

Received 19 May 2014; Revised 20 July 2014; Accepted 11 August 2014; Published 2 September 2014

Academic Editor: Xilin Chen

Copyright (c) 2014 Yanhong Zhao et al. This is an open access article distributed under the Creative Commons Attribution License, which permits unrestricted use, distribution, and reproduction in any medium, provided the original work is properly cited.

Graphene/ZnO composites with different contents of $\mathrm{ZnO}$ have been successfully synthesized via a liquid phase route. The structure, morphology, and electrochemical performances of the composites are investigated by XRD, Raman, SEM, TEM, AFM, and electrochemical measurement. The results reveal that $\mathrm{ZnO}$ nanoparticles wedged on the surface of the graphene nanosheets. The initial capacity of graphene/ZnO $(1: 1)$ reached $1155.27 \mathrm{mAh} \mathrm{g}^{-1}$, which increased $162.87 \mathrm{mAh} \mathrm{g}^{-1}$ compared with the initial capacity of graphene. This could be attributed to the unique structure of the prepared composite and synergies of graphene and $\mathrm{ZnO}$ in the lithium ion storage.

\section{Introduction}

Lithium ion batteries (LIBs) are essential components for hand-held electronic devices, electrical vehicles, and so forth [1]. In order to meet the demand of the practical applications, the electrode materials of LIBs should have high reversible capacity, good cycling performance, fine conductivity, and large energy volume density [2]. Graphene is widely used as electrode material because of its excellent electrical conductivity, large specific surface area, and flexibility. But graphene could not be used as anode material due to the high irreversible capacity and the low first coulombic efficiency [3-6]. This may be related to its stacking and large specific surface. The stacking will decrease the storage space of lithium ion. The large specific surface could lead to the more probability to produce solid electrolyte interphase (SEI) because of the reaction between lithium ion and electrolyte on the graphene sheets surface, which increases the irreversible capacity of graphene as the anode. Some metal oxides have been introduced for improving these shortcomings of graphene, such as $\mathrm{Co}_{3} \mathrm{O}_{4}$ [7] and $\mathrm{SnO}_{2}$ [8]. The metal oxide nanoparticles can enter the layers of graphene sheets and prevent graphene sheets (GNS) from stacking together. Also the GNS can prevent the aggregation of metal oxide nanoparticles, which makes a significant contribution to improving the conductivity of the composite. Compared to these materials, $\mathrm{ZnO}$ has a theoretical capacity of $978 \mathrm{mAh} \mathrm{g}^{-1}$ [9], which makes it possible for the application as an anode material for lithium ion batteries, while $\mathrm{ZnO}[10,11]$ is rarely studied in terms of lithium ion battery due to severe expansion and contraction during charge and discharge and low electrical conductivity [12]. So graphene and $\mathrm{ZnO}$ are composited together, which will restrain the reuniting of graphene and alleviating the volume effect of $\mathrm{ZnO}$.

Based on the above analysis, graphene/ $\mathrm{ZnO}$ composites with different percentages of $\mathrm{ZnO}$ have been successfully synthesized by a facile liquid phase method. The structure and morphology of the composites are investigated by XRD, Raman, SEM, TEM, and AFM. Electrochemical performance of composites (used as reversible anode materials for lithium ion batteries) is investigated. The composite has higher reversible capacity and coulombic efficiency than graphene, which recommends it as a promising alternative anode material used for high energy lithium ion batteries.

\section{Material and Methods}

First, graphene oxide (GO) was prepared by modified Hummers' method [13]. Second, GO was exfoliated through ultrasonication process. The $0.1 \mathrm{~g}$ graphene oxide was added to $10 \mathrm{~mL}$ DI water and solution underwent sonication for 


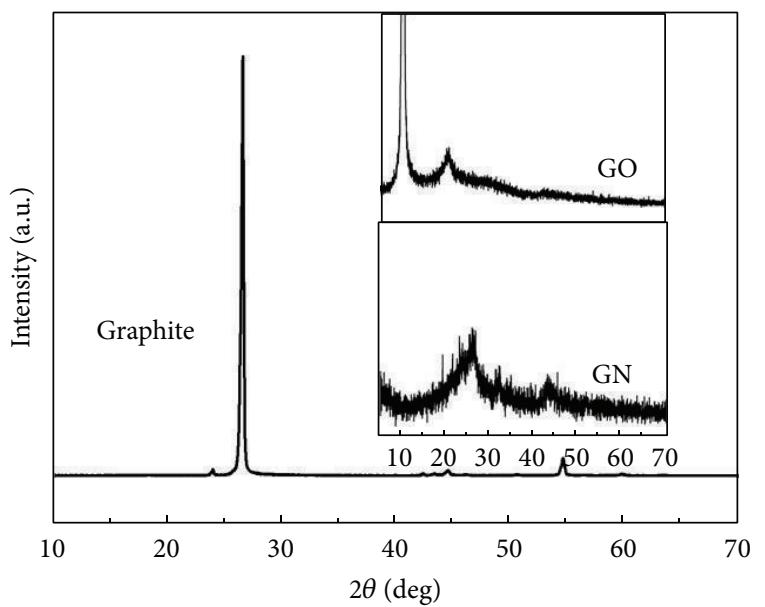

(a)

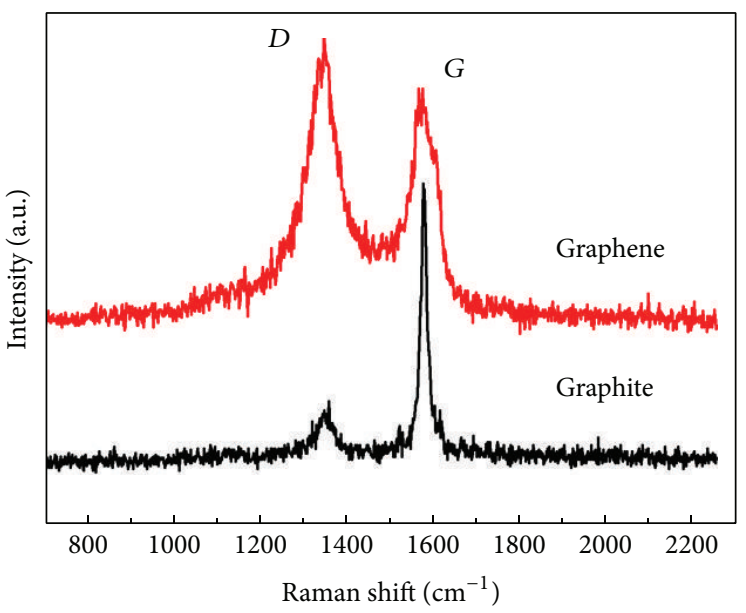

(b)

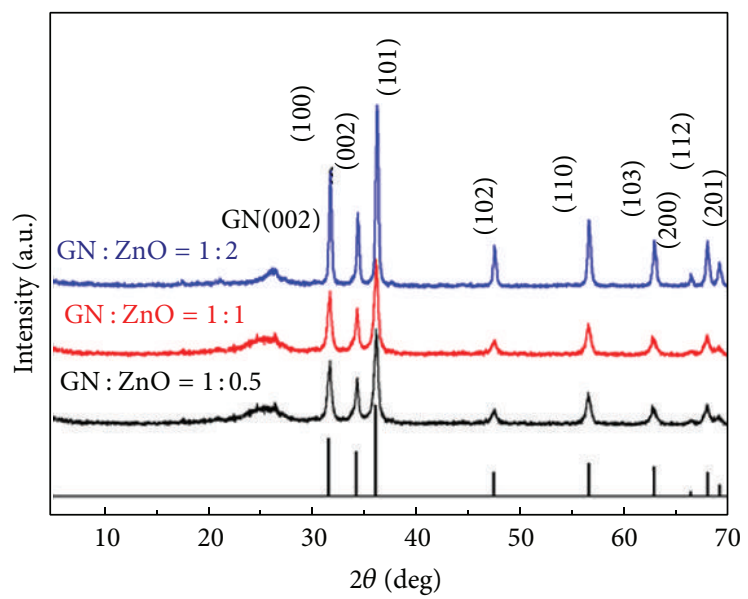

(c)

FIGURE 1: XRD pattern of (a) graphite, graphene oxide, and graphene, (b) graphene/ZnO composite and Raman spectrum of graphene sheets and graphite (c).

$90 \mathrm{~min}$. In third step, zinc acetate solution was slowly added into GO solution as $0.5: 1,1: 1$, and $2: 1$ and the product after drying was heated at $300^{\circ} \mathrm{C}$ for $6 \mathrm{~h}$ to remove oxide functional groups and residual water molecules. For the comparative study of the electrochemical performance, pure $\mathrm{ZnO}$ and reduced graphene oxide were also prepared.

Product was characterized using powder X-ray diffraction (XRD, Bruker D-8 Advance), Raman spectroscopy (JY HR-800, $532 \mathrm{~nm}$ ), atomic force microscope (AFM, Dimension Icon), scanning electron microscopy (SEM, FESEM, Quanta 200F, FEI), and transmission electron microscopy (TEM, JEM-2010FEF, $200 \mathrm{kV}$ ).

Electrochemical performances of graphene, $\mathrm{ZnO}$, and graphene/ $\mathrm{ZnO}$ composites were investigated with coin-type cells (CR2025). The working electrodes were prepared by a slurry (80 wt $\%$ active material, $10 \mathrm{wt} \%$ polyvinylidene fluoride (PVDF) in $\mathrm{N}$-methyl pyrrolidone (NMP), and $10 \mathrm{wt} \%$ carbon black) coating procedure. Test cells were assembled in an argon-filled glove box with the metallic lithium foil as the reference and counter electrodes. The electrolyte was $1.0 \mathrm{~mol} \mathrm{dm}^{-3} \mathrm{LiPF}_{6}$ in a mixture of ethylene carbonate (EC) and dimethyl carbonate (DMC). The electrochemical characterizations were measured by charging and discharging in the range of $0.01-3.0 \mathrm{~V}$ (versus $\mathrm{Li} / \mathrm{Li}^{+}$) at room temperature using a battery test system (LAND, Wuhan Jinnuo Electronics Ltd.). AC impedance measurement was carried out using a CHI604C (Shanghai Huachen Electronics Ltd.) electrochemical working station in the $100 \mathrm{KHz}$ to $10 \mathrm{mHz}$ frequency range.

\section{Results and Discussion}

XRD patterns of graphite, graphene oxide (GO), and graphene are shown in Figure 1(a). The little patterns in Figure $1(\mathrm{a})$ indicate graphene $(\mathrm{GN})$ was completely reduced from GO. The diffraction peak of GN at $26.6^{\circ}$ which appeared with low intensity compared with graphite indicates that the reduced graphene sheets are less compact and more disorderly stacked. Figure 1(b) shows Raman spectrum of graphite and graphene. Two main peaks (D and $G$ ) are observed in Raman spectra. The $\mathrm{D}$ band is assigned to $\mathrm{A}_{1 \mathrm{~g}}$ phonon of $\mathrm{sp}^{3}$ carbon atoms of disordered graphite, and the $G$ band is 
related to the in-plane vibration of $\mathrm{sp}^{2}$ carbon atom $[14,15]$. The $\mathrm{D} / \mathrm{G}$ intensity ratio $\left(I_{\mathrm{D}} / I_{\mathrm{G}}=1.2\right)$ of graphene is larger than graphite. The significant increase of $D / G$ intensity ratio is due to the decrease in the size of the in-plane $\mathrm{sp}^{2}$ domains, as well as an increase in the edge planes. Figure 1(c) shows the XRD patterns of graphene/ $\mathrm{ZnO}$ composite and standard $\mathrm{ZnO}$. The diffraction peaks of composites are indexed well to $\mathrm{ZnO}$ (JCPDS no. 36-1451) without any impurities [16], and the 002 peak of graphene is still at $26.6^{\circ}$. This result indicates that high crystallinity and uniformity of $\mathrm{ZnO}$ or graphene are obtained and the crystal structure of $\mathrm{ZnO}$ and graphene does not change.

The detailed morphologies of graphene and graphene/ $\mathrm{ZnO}$ can be known by TEM images, as shown in Figure 2 . Figure 2(a) exhibits that graphene has a flat lamellar structure. Such structure could make graphene have large surface and increase the lithium storage location. On the other hand, the wrinkle can be seen which could form some little space. That could keep in the storage of lithium ion. The few layers of graphene could be seen in the HRTEM image of Figure 2(c). Figure 2(e) is the AFM images of the graphene sheets. Figure 2(f) is the three-dimensional image of Figure 2(e). The results of HRTEM and AFM show that the thickness of the prepared graphene is $3 \mathrm{~nm}$. Because the single layer is $0.335 \mathrm{~nm}$, the synthesized graphene has about 8 layers. Figure 2(b) shows that $\mathrm{ZnO}$ nanoparticles uniformly wedge in flat graphene nanosheets; the average size of $\mathrm{ZnO}$ nanoparticles is about $20-50 \mathrm{~nm}$. The graphene nanosheets and $\mathrm{ZnO}$ nanoparticles closely contact with each other. Flat sheet of graphene and close contact of graphene and $\mathrm{ZnO}$ are beneficial to the lithium ion diffusion and electron transfer. Furthermore, the graphene sheet nanostructure is staggered and stacked together to form large conductive network.

In order to confirm that the composite could have enhanced electrochemical performance, the charge/discharge test, cyclic performances, and Nyquist plots were carried out, as shown in Figure 3. Figure 3(a) shows that the initial discharge and charge capacity of graphene/ZnO $(1: 0.5,1: 1$, and $1: 2$ ) and graphene at the rate of $100 \mathrm{~mA} \mathrm{~g}^{-1}$ are 1028.8 and $582.3 \mathrm{mAh} \mathrm{g}^{-1}, 1155.27$ and $650.79 \mathrm{mAh} \mathrm{g}^{-1}, 737.9$ and $431.55 \mathrm{mAhg}^{-1}, 992.4$ and $537.9 \mathrm{mAhg}^{-1}$, respectively. The capacity of graphene is more than theoretical capacity $\left(744 \mathrm{mAhg}^{-1}\right)$ because of its wrinkle and stacking. The reformation space could store more lithium ion. The composite materials with mass rate of $1: 0.5$ and $1: 1$ have high capacity exceeding theoretical capacities of graphene or $\mathrm{ZnO}$. The capacity of graphene/ZnO is higher than graphene or $\mathrm{ZnO}$, which is attributed to the novel structure of the composite. $\mathrm{ZnO}$ particles are wedged in the surface of the flat graphene and support the large flat sheet of graphene, which reduce graphene overlapping and retain the lithium storage space. In addition, $\mathrm{ZnO}$ nanoparticles uniformly disperse on the surface of graphene sheets; the volume expansion of $\mathrm{ZnO}$ was limited by the flexible graphene sheets. So the combination of graphene and $\mathrm{ZnO}$ can effectively prevent the aggregation of $\mathrm{ZnO}$ nanoparticles and the restacking of graphene. All these ensure that the electronic transfer network is unobstructed, integrated and stable. So
graphene/ZnO composite will have the advanced capacity more than the single graphene or $\mathrm{ZnO}$.

In Figure 3(b), the initial charge capacity of graphene/ $\mathrm{ZnO}(1: 1)$ is $650.79 \mathrm{mAh} \mathrm{g}^{-1}$, while the graphene electrode shows an initial charge capacity of $537.9 \mathrm{mAh} \mathrm{g}^{-1}$. This is because of the novel structure of the composite. As can be seen in Figure 2(b), $\mathrm{ZnO}$ was wedged in the surface of graphene, which not only supported the flat sheet of graphene, but also occupied the part of active position. In the place, the lithium ion cannot react with electrolyte, so the irreversible amount of lithium ion was reduced. As can be seen in Figure 3(b), the graphene exhibited a specific capacity of $357 \mathrm{mAh} \mathrm{g}^{-1}$, and the graphene/ZnO composite was $401 \mathrm{mAhg}^{-1}$. However, $\mathrm{ZnO}$ presented a very poor cycling performance because its constructive structure collapsed with volume expansion and contraction in charge and discharge. So $\mathrm{ZnO}$ wedged in the graphene which enhanced the reversible capacity of the material.

Figure 3(c) depicts the Nyquist plots of graphene and graphene/ZnO. The semicircle in the middle frequency range indicates the charge transfer resistance, and the inclined line in the low-frequency range represents the Warburg impedance [17]. It can be clearly seen that the charge transfer resistance of graphene/ $\mathrm{ZnO}$ electrode is smaller than graphene. Because graphene and $\mathrm{ZnO}$ form the stereochemical structure, they influence each other and produce synergy. Their synergy improves the lithium ion diffusion and the electronic transfer and enhances the lithium storage capacity.

\section{Conclusions}

In summary, the graphene/ $\mathrm{ZnO}$ composite is prepared as an anode for lithium ion battery via a liquid phase route. The $\mathrm{ZnO}$ nanoparticles with an average particle size of $20-50 \mathrm{~nm}$ uniformly wedge in the graphene nanosheets. It exhibits the high specific capacity of $1155.27 \mathrm{mAh} \mathrm{g}^{-1}$ at $100 \mathrm{~mA} \mathrm{~g}^{-1}$ and the initial charge capacity of $650.79 \mathrm{mAhg}^{-1}$ with $56.3 \%$ coulombic efficiency, all are superior to the graphene. The enhanced electrochemical performance is due to the synergistic effect, which can improve the lithium ion transfer and the electronic transmitted between $\mathrm{ZnO}$ nanoparticles and graphene nanosheets. So graphene/ $\mathrm{ZnO}$ composite can be used as an ideal candidate for anode material of highperformance lithium ion batteries.

\section{Conflict of Interests}

The authors declare that there is no conflict of interests regarding the publication of this paper.

\section{Acknowledgments}

This work was financially supported by the projects of Natural Science Foundation of China (21271055), Open Project of 


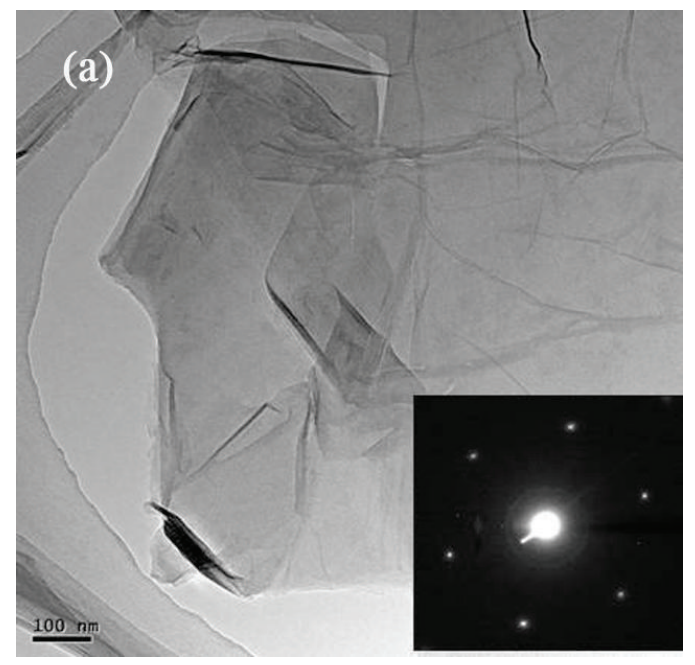

(a)

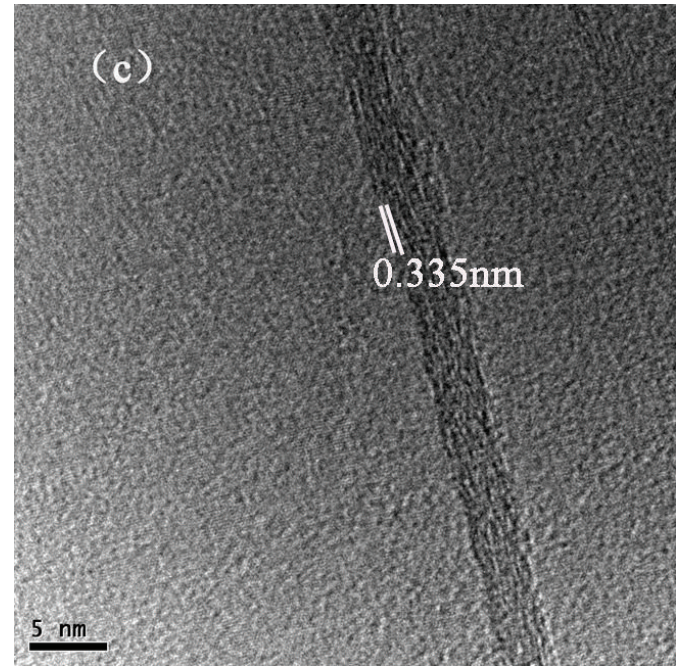

(c)
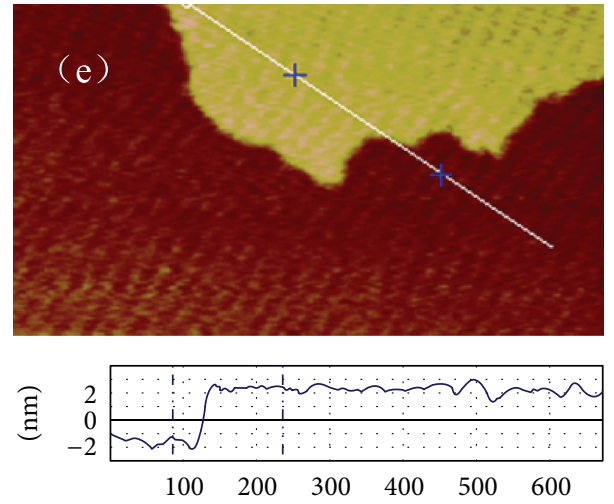

(e)

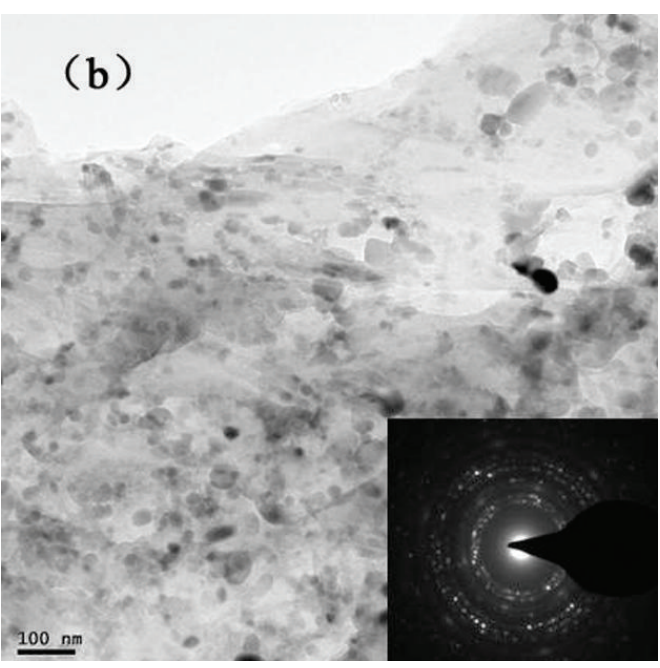

(b)

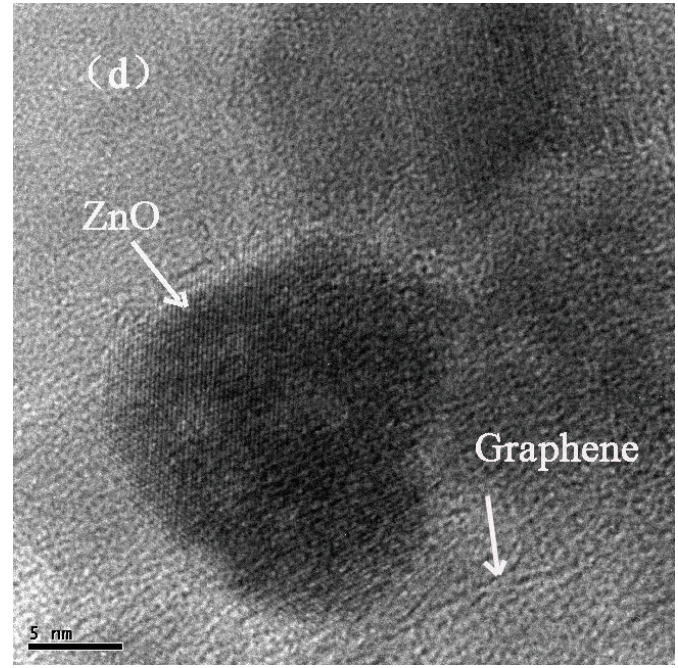

(d)

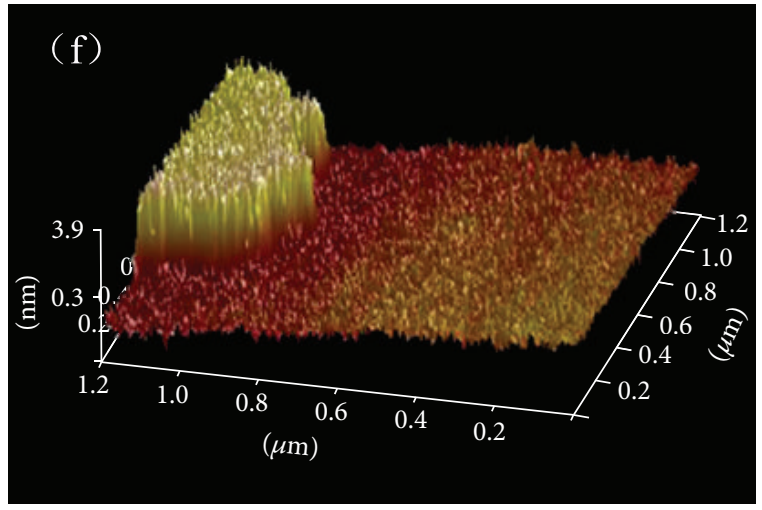

(f)

FIGURE 2: TEM image of graphene sheets ( $a, c)$, graphene/ZnO (b, d), and AFM image of graphene sheets with height profile (e) and 3D (f). 


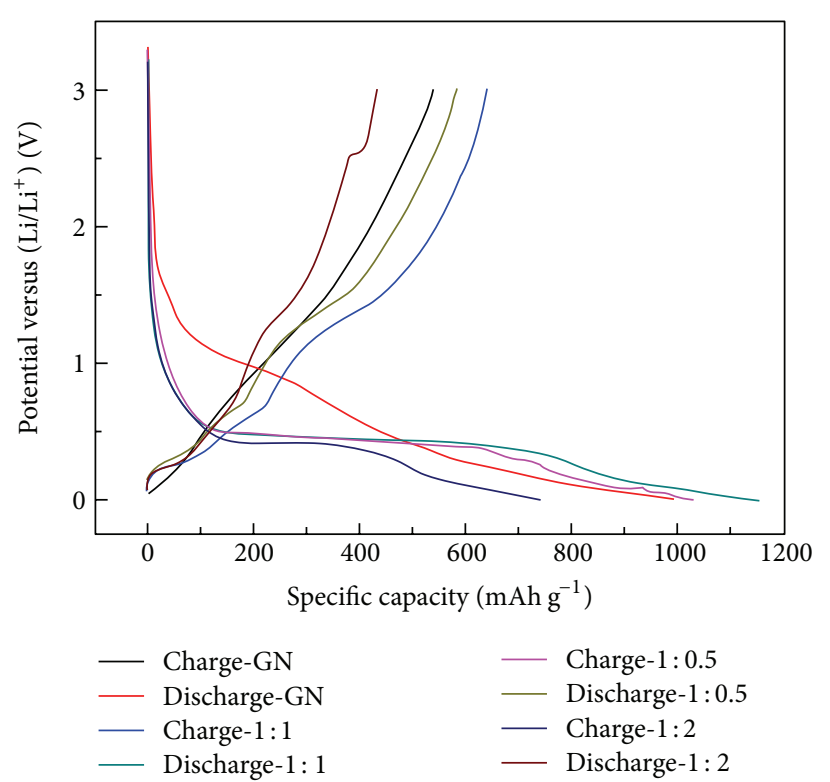

(a)

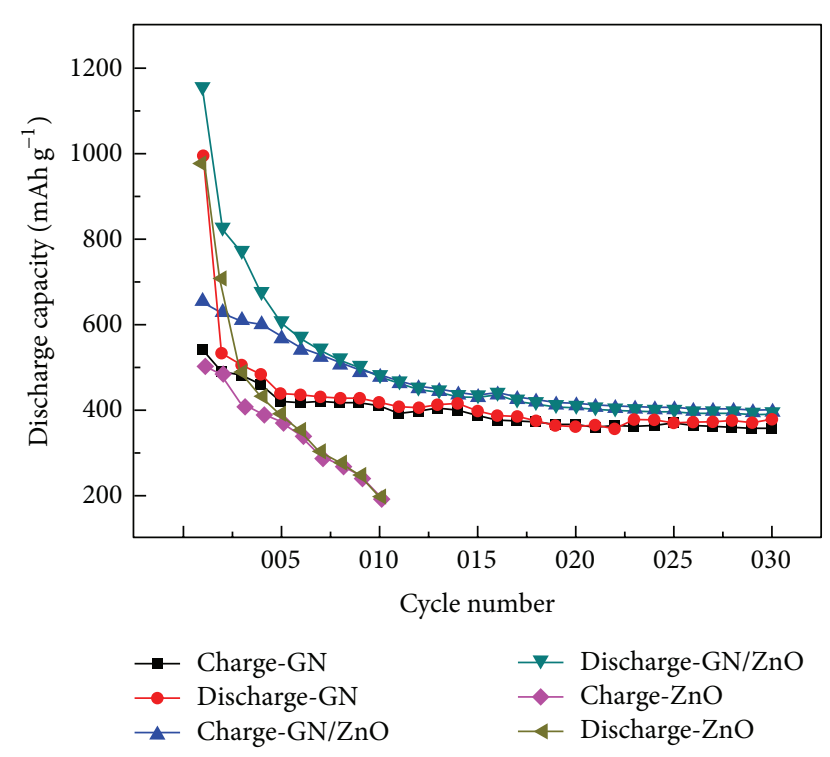

(b)

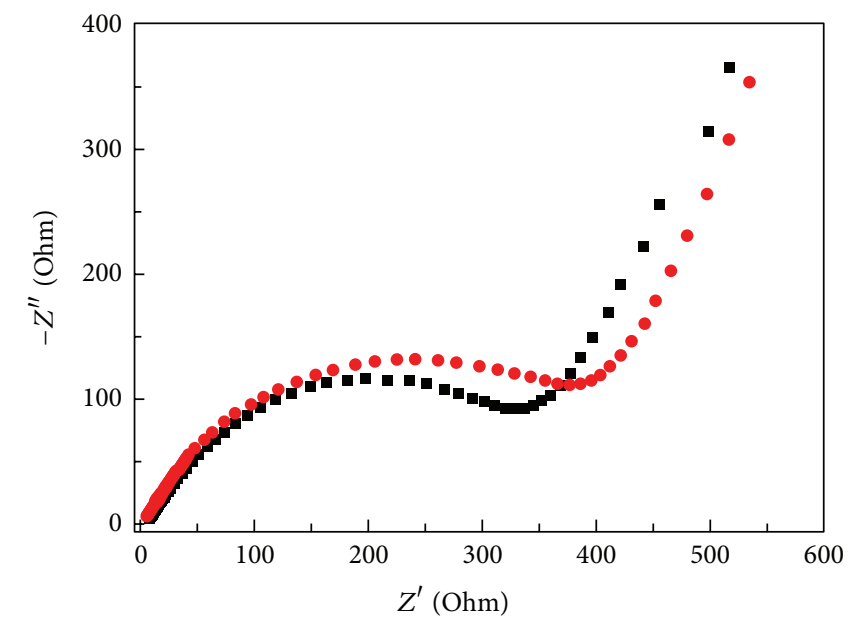

- $\mathrm{GN} / \mathrm{ZnO}$

- GN

(c)

Figure 3: The first discharge/charge curves for graphene and graphene/ZnO composite (a), cycle performance of graphene sheets, graphene/ZnO, and pure $\mathrm{ZnO}$ at $100 \mathrm{~mA} \mathrm{~g}^{-1}$ (b), EIS spectra of graphene/ZnO and graphene after 2nd cycle discharge/charge (c).

State Key Laboratory of Urban Water Resource and Environment, Harbin Institute of Technology (no. QAK201304), and Youth Science Foundation of Heilongjiang Province in China (no. QC2012C079).

\section{References}

[1] H.-K. Song, K. T. Lee, M. G. Kim, L. F. Nazar, and J. Cho, "Recent progress in nanostructured cathode materials for lithium secondary batteries," Advanced Functional Materials, vol. 20, no. 22, pp. 3818-3834, 2010.

[2] R. Marom, S. F. Amalraj, N. Leifer, D. Jacob, and D. Aurbach, "A review of advanced and practical lithium battery materials,"
Journal of Materials Chemistry, vol. 21, no. 27, pp. 9938-9954, 2011.

[3] V. Singh, D. Joung, L. Zhai, S. Das, S. I. Khondaker, and S. Seal, "Graphene based materials: past, present and future," Progress in Materials Science, vol. 56, no. 8, pp. 1178-1271, 2011.

[4] S. J. Guo and S. J. Dong, "Graphene nanosheet: synthesis, molecular engineering, thin film, hybrids, and energy and analytical applications," Chemical Society Reviews, vol. 40, no. 5, pp. 26442672, 2011.

[5] P. Guo, H. Song, X. Chen, L. Ma, G. Wang, and F. Wang, "Effect of graphene nanosheet addition on the electrochemical performance of anode materials for lithium-ion batteries," Analytica Chimica Acta, vol. 688, no. 2, pp. 146-155, 2011. 
[6] D. A. Dikin, S. Stankovich, E. J. Zimney et al., "Preparation and characterization of graphene oxide paper," Nature, vol. 448, no. 7152, pp. 457-460, 2007.

[7] Y. Xiao, C. W. Hu, and M. H. Cao, "High lithium storage capacity and rate capability achieved by mesoporous $\mathrm{Co}_{3} \mathrm{O}_{4}$ nanobundles," Journal of Power Sources, vol. 247, pp. 49-56, 2014.

[8] Y. Li, X. Lv, J. Lu, and J. Li, "Preparation of $\mathrm{SnO}_{2}$-nanocrystal/ graphene-nanosheets composites and their lithium storage ability," Journal of Physical Chemistry C, vol. 114, no. 49, pp. 2177021774, 2010.

[9] J. P. Liu, Y. Li, R. Ding et al., "Carbon/ZnO nanorod array electrode with significantly improved lithium storage capability," Journal of Physical Chemistry C, vol. 113, no. 13, pp. 5336-5339, 2009.

[10] Y. Chen, J. Lu, and Z. Gao, "Structural and electronic study of nanoscrolls rolled up by a single graphene sheet," The Journal of Physical Chemistry C, vol. 111, no. 4, pp. 1625-1630, 2007.

[11] J. Liu, Y. Li, R. Ding et al., "Carbon/ZnO nanorod array electrode with significantly improved lithium storage capability," Journal of Physical Chemistry C, vol. 113, no. 13, pp. 5336-5339, 2009.

[12] Z. Wu, L. Qin, and Q. Pan, "Fabrication and electrochemical behavior of flower-like $\mathrm{ZnO}-\mathrm{CoO}-\mathrm{C}$ nanowall arrays as anodes for lithium-ion batteries," Journal of Alloys and Compounds, vol. 509, no. 37, pp. 9207-9213, 2011.

[13] W. S. Hummers Jr. and R. E. Offeman, "Preparation of graphitic oxide," Journal of the American Chemical Society, vol. 80, no. 6, p. $1339,1958$.

[14] G. Wang, X. Shen, J. Yao, and J. Park, "Graphene nanosheets for enhanced lithium storage in lithium ion batteries," Carbon, vol. 47, no. 8, pp. 2049-2053, 2009.

[15] S. Stankovich, D. A. Dikin, R. D. Piner et al., "Synthesis of graphene-based nanosheets via chemical reduction of exfoliated graphite oxide," Carbon, vol. 45, no. 7, pp. 1558-1565, 2007.

[16] T. Lu, Y. Zhang, H. Li, L. Pan, Y. Li, and Z. Sun, "Electrochemical behaviors of graphene- $\mathrm{ZnO}$ and graphene- $\mathrm{SnO}_{2}$ composite films for supercapacitors," Electrochimica Acta, vol. 55, no. 13, pp. 4170-4173, 2010.

[17] Y. J. Mai, X. L. Wang, J. Y. Xiang et al., "CuO/graphene composite as anode materials for lithium-ion batteries," Electrochimica Acta, vol. 56, no. 5, pp. 2306-2311, 2011. 

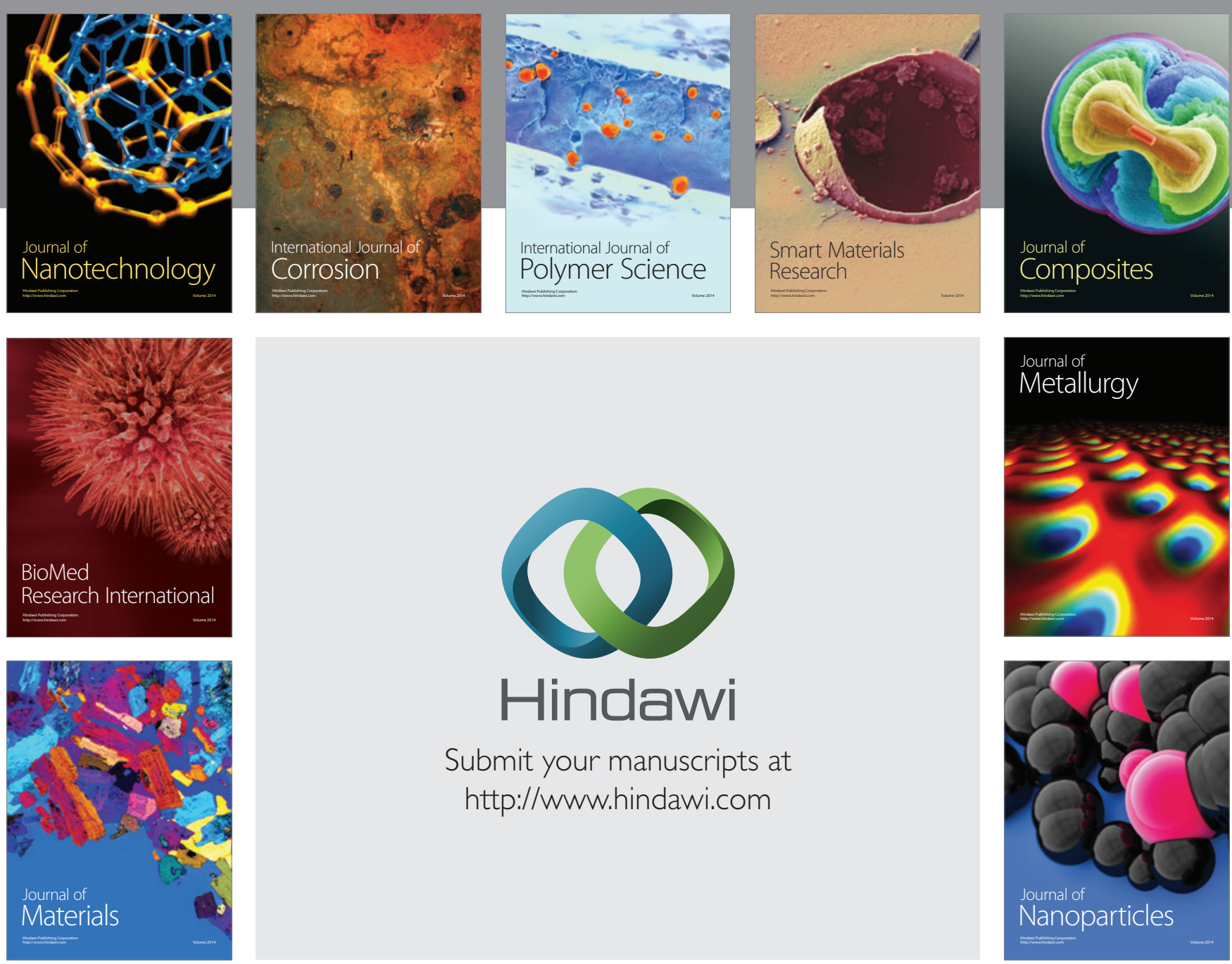

Submit your manuscripts at http://www.hindawi.com
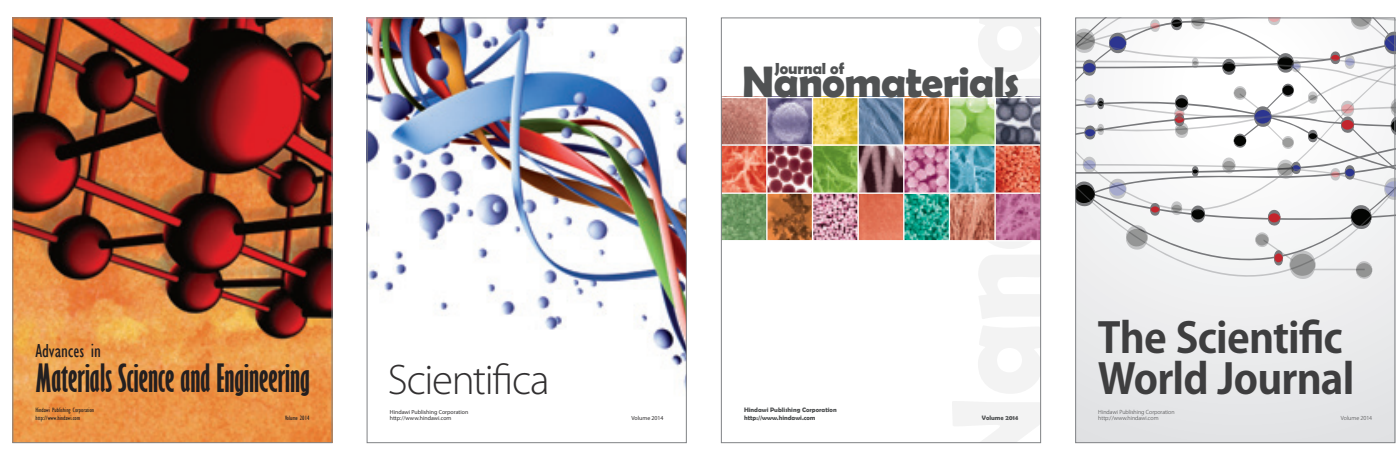

\section{The Scientific World Journal}
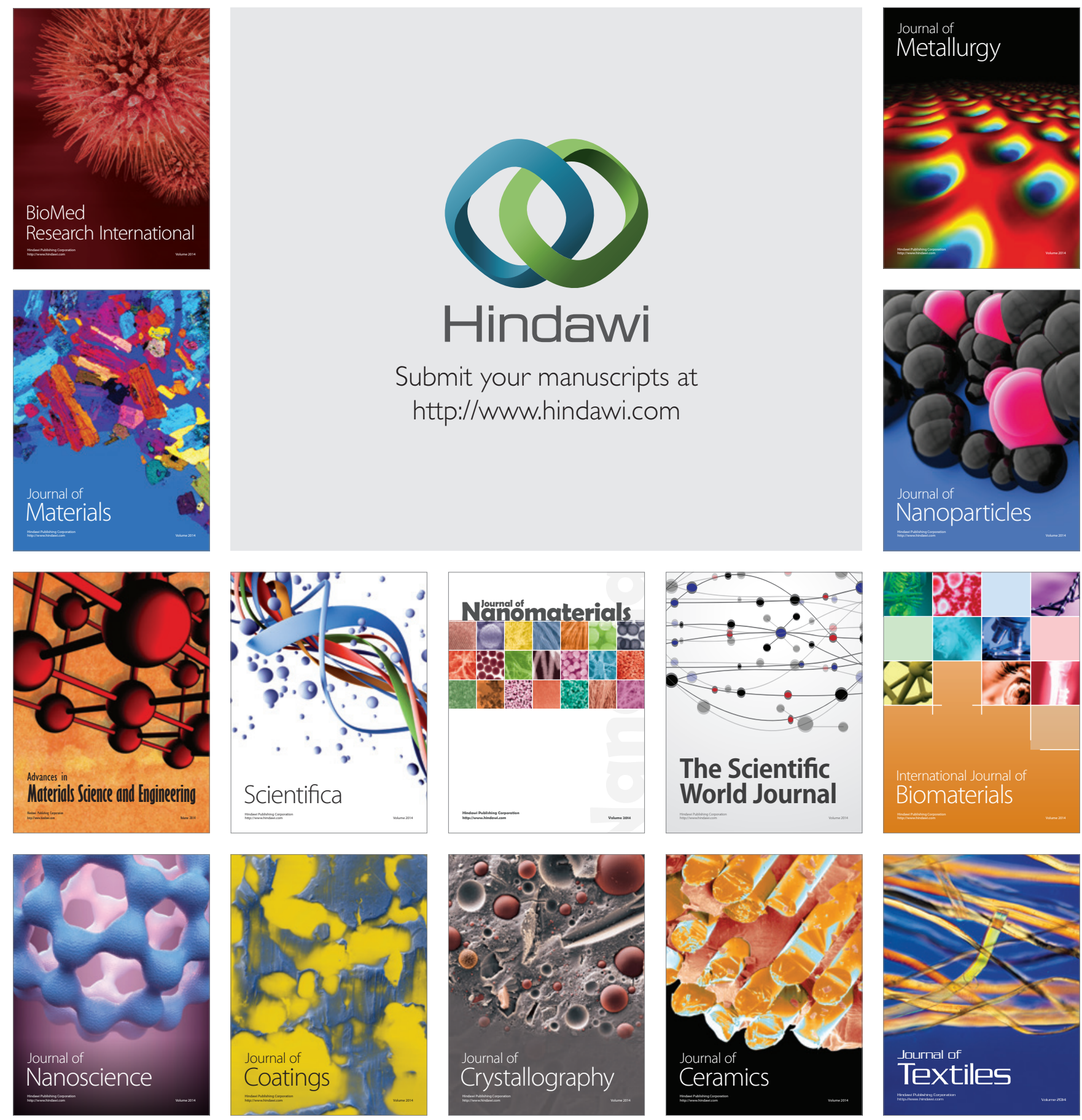